\title{
Control of Integrated Powertrain With Electronic Throttle and Automatic Transmission
}

\author{
Daekyun Kim, Huei Peng, Shushan Bai, and Joel M. Maguire
}

\begin{abstract}
A process to design the control strategy for a vehicle with electronic throttle control (ETC) and automatic transmission is proposed in this paper. The driver's accelerator pedal position is interpreted as a power request, which is to be satisfied by coordinating the transmission gear shift and the throttle opening in an optimal fashion. The dynamic programming (DP) technique is used to obtain the optimal gear shift and throttle opening which maximizes fuel economy while satisfying the power demand. The optimal results at different power levels are then combined to form a gear map and a throttle map which governs the operation of the integrated powertrain. A control architecture concept is presented where the relationship between the accelerator pedal position and the power demand level can be adjusted according to the preference of the vehicle performance target. Simulation, vehicle test, and dynamometer test results show that the proposed integrated powertrain control scheme produces power consistently and improves fuel efficiency compared with conventional powertrain control schemes.
\end{abstract}

Index Terms-Automatic transmission, dynamic programming (DP), electronic throttle control, gear shift map, integrated powertrain control.

\section{INTRODUCTION}

$\mathbf{I}^{2}$ $\mathrm{N}$ conventional vehicles powered by gasoline engines, the accelerator pedal actuated by the driver is mechanically linked to the engine throttle which regulates the airflow to the intake manifold. When the driver holds the accelerator pedal constant, the power and torque generated by the engine will change with engine speed, and thus, the driver needs to vary the pedal position to obtain constant torque (acceleration) or power from the engine. Since each powertrain has its own torque/power characteristics, drivers bear the responsibility to adapt to the powertrain, instead of the other way around. The mechanical linkage between accelerator pedal to the throttle is replaced by an electronic connection, commonly known as electronic throttle control (ETC) [1], [2] in modern vehicles. ETC provides flexibility between the pedal to throttle mapping and, thus, a new design degree-of-freedom. For example, it

\footnotetext{
Manuscript received October 30, 2006; revised January 8, 2007. Manuscript received in final form January 25, 2007. Recommended by Associate Editor K. Butts. This work was supported by General Motors Powertrain.

D. Kim was with the Department of Mechanical Engineering, University of Michigan, Ann Arbor, MI 48109-2121 USA. He is now with Research and Development and Strategic Planning, General Motors, Warren, MI 48090-9055 USA (e-mail: andrew.kim@gm.com).

H. Peng is with the Department of Mechanical Engineering, University of Michigan, Ann Arbor, MI 48109-2121 USA (e-mail: hpeng@umich.edu).

S. Bai is with the General Motors Powertrain, Ypsilanti, MI 48197-0935 USA (e-mail: shushan.bai@gm.com).

J. M. Maguire is with the General Motors Powertrain, Pontiac, MI 48340-

2920 USA (e-mail: joel.m.maguire@gm.com).

Digital Object Identifier 10.1109/TCST.2007.894641
}

can be used to realize and integrate features such as idle speed control, cruise control, adaptive cruise control, traction control, etc. In this paper, we investigate an integrated powertrain control feature, which coordinates the control of transmission (gear shifting) and engine (throttle). The design goal is to satisfy the driver's power demand while optimizing fuel economy.

For modern powertrain systems equipped with ETC, many studies explored the possible advantage of controlling the throttle opening angle during a gear shift. In [3], Ge et al. present a control algorithm to minimize the reduction in vehicle performance and deterioration of shift quality due to the sudden change of the gear ratio. Using a closed-loop control scheme, the throttle opening is adjusted during the shift to reduce the speed difference between the synchronized gears in the gearbox and the speed difference between the driving and the driven plates of the clutch. Minowa et al. [4] interpreted the accelerator pedal position as a drive shaft torque demand. The throttle opening can then be controlled to compensate for the torque reduction caused by the selection of the gear shift timing for minimum fuel consumption. The method was found to be promising in improving fuel economy and acceleration feel. Yasuoka et al. [5] presented an integrated control algorithm for a powertrain system with ETC and continuously variable transmission (CVT). Target engine torque and target CVT ratio to achieve the demanded drive torque with optimum fuel economy is determined based on the gear ratio map and drive torque demand. Moreover, to improve the torque response during a transient, the engine torque is used to compensate for the lag in inertia torque and the gear ratio change response. Sakaguchi et al. [6] asserts that to improve fuel efficiency the entire powertrain, including engine and transmission, need to be considered rather than just focusing on the engine. For a vehicle equipped with CVT, an algorithm to calculate the engine torque and CVT ratio combinations achieving the highest overall efficiency for the powertrain is developed.

When an advanced powertrain is equipped with electronic throttle, the accelerator pedal is no longer linked with the engine throttle plate. Therefore, the detected pedal motion needs to be interpreted as a driver demand, typically either as a torque demand or a power demand. In this paper, the accelerator pedal position is interpreted as a request for power for two reasons. First, the definition of an "ideal powertrain" is a power source that produces power in a reliable way. The other is that according to a study by Vahabzadeh et al. [7], engine power was found to be the best physical measurable parameter representing the driver's demand.

In this paper, we will develop throttle/gear maps that satisfy driver's power demand, and in the meantime, achieve optimal fuel economy. First, a vehicle model that is accurate enough 
to emulate a target vehicle is created. The model includes submodels for an engine, a torque converter, a transmission gear box, and the tire/vehicle dynamics. The model is validated against a wide open throttle field test data in addition to the EPA fuel economy cycle tests. The simulation model is then simplified to obtain a control design model for the dynamic programming (DP) process, with all the state and input variables discretized into manageable numbers of grid points. Vehicle launch at selected constant pedal positions (i.e., constant power request) are used as the maneuvers for our optimization process. A DP problem with fuel economy and power production error as the cost function was then solved for each of these maneuvers. The optimal inputs (throttle opening and gear shift) are obtained for each maneuver at constant power request. Results from all the power levels are then combined to form a throttle map and a gear map. The obtained throttle map and gear map are implemented in the vehicle simulation model and are tested for fuel economy by running the EPA fuel economy cycle. Finally, the maps are implemented in the test vehicle and are evaluated for fuel economy, performance, and comfort.

\section{Vehicle Simulation Model}

In this section, the simulation model of the target vehicle system is described. This model will be used to test fuel economy and drivability of the powertrain control strategies. It will also serve as the basis for the model of the DP optimization. The model needs to be accurate enough to emulate the behavior of the target vehicle yet possess minimal complexity. The model is composed of two main components: the powertrain and the tire/vehicle body. The powertrain is further divided into three subcomponents: the engine, the torque converter, and the transmission gearbox. The powertrain is subdivided in this manner to anticipate future modifications of these subcomponents into various different component systems such as engines with variable cylinder activation technology, diesel engines, six-speed ATs, CVTs, etc. The math-based optimization procedure established in this study is not confined to powertrain systems with conventional subcomponents but is meant as the backbone for control design of general powertrains. For the tire/vehicle body, only the longitudinal dynamics is considered since, in general, fuel economy and drivability of a vehicle are measured only in regards to the longitudinal motion of the vehicle.

The vehicle model is structured in the Matlab/SIMULINK environment, as shown in Fig. 1. The target vehicle for this study is a two-wheel drive production pickup truck with a $5.3-\mathrm{L} \mathrm{V8}$ engine equipped with ETC and a four-speed AT. Parameters of the truck are shown in Table I.

\section{A. Engine}

The engine angular speed $N_{e}$ is calculated from the engine rotational dynamics

$$
\left(J_{e}+J_{p}\right) \times \dot{N}_{e}=T_{e}-T_{p}-\left(T_{p l}+T_{a l}\right)
$$

where $J_{e}$ and $J_{p}$ are the rotational inertia of the engine and the torque converter pump, $T_{e}$ and $T_{p}$ are the engine torque and the

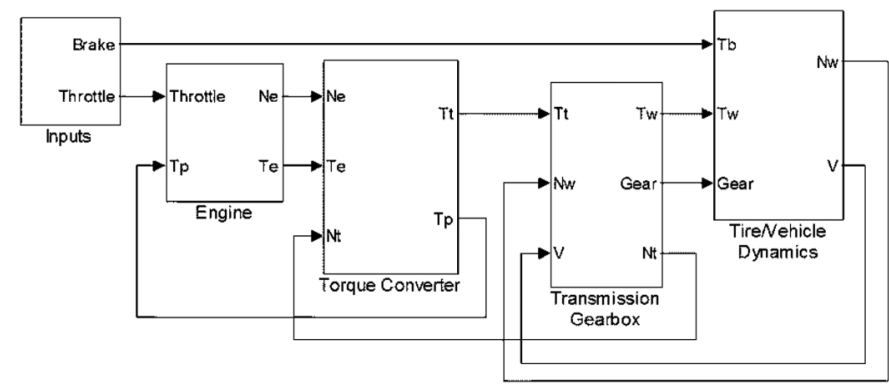

Fig. 1. Vehicle simulation model in SIMULINK blocks.

TABLE I

VEHICLE PARAMETERS

\begin{tabular}{ll}
\hline Vehicle mass & $2805 \mathrm{~kg}$ \\
Rolling radius of tire & $0.371 \mathrm{~m}$ \\
Final drive ratio & 3.42 \\
Inertia of wheel + axle & $2.5 \mathrm{~kg} \cdot \mathrm{m}^{2}$ \\
Coefficient of rolling resistance & 0.015 \\
Coefficient of air drag & 0.4 \\
Frontal area & $1.81 \mathrm{~m} \times 1.99 \mathrm{~m}$ \\
Gear ratio & $3.060,1.625,1.000,0.696$ \\
Gear efficiency & $0.987,0.987,1.000,0.994$ \\
Equivalent gear inertia & $0.362 \mathrm{~kg} \cdot \mathrm{m}^{2}, 0.066 \mathrm{~kg} \cdot \mathrm{m}^{2}$, \\
& $0.067 \mathrm{~kg} \cdot \mathrm{m}^{2}, 0.066 \mathrm{~kg} \cdot \mathrm{m}^{2}$ \\
\hline
\end{tabular}

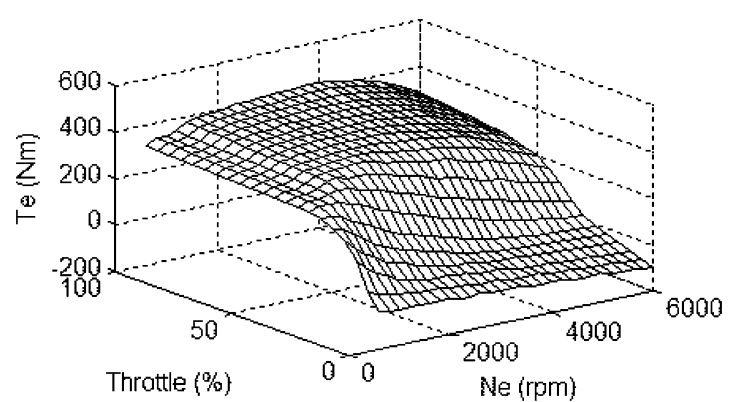

(a)

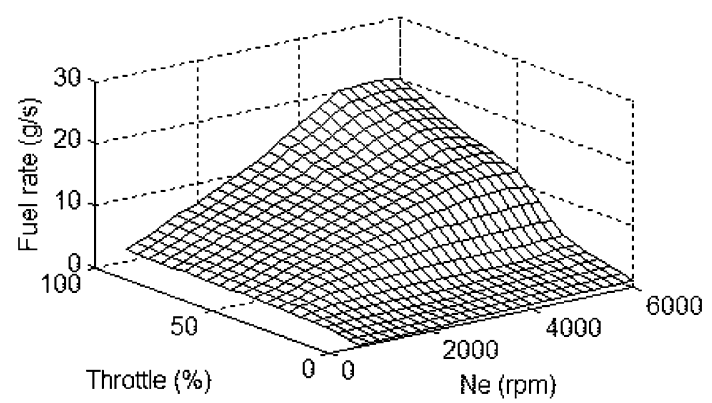

(b)

Fig. 2. (a) Engine torque map. (b) Engine fuel rate map.

torque converter pump torque, $T_{p l}$ is the pump spin loss, and $T_{a l}$ is the accessories loss torque. The engine torque is obtained from a steady-state map [see Fig. 2(a)] which is a function of throttle opening and $N_{e}$. The torque converter pump torque is calculated from (3) shown in Section II-B. The pump loss is based on engine speed and throttle opening. The accessories loss torque is only dependent on the engine speed. The fuel consumption of the vehicle is calculated using a steady-state map 


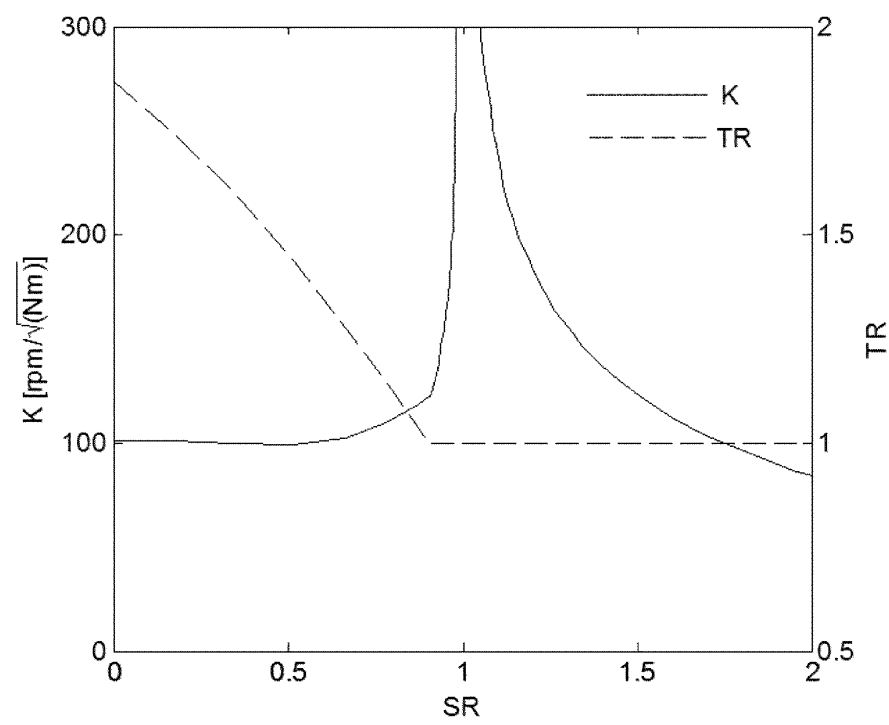

Fig. 3. Torque converter characteristics.

in the same manner as the engine torque [see Fig. 2(b)]. These steady-state maps, shown in Fig. 2, are based on tests of the engine.

\section{B. Torque Converter}

A torque converter consists of a pump which is connected to the output shaft of the engine, a turbine connected to the shaft going to the transmission gear sets, and a stator grounded to a one-way clutch. In this study, the torque converter is represented by a static, nonlinear input-output (I/O) model as

$$
\begin{aligned}
T_{p} & =\left(\frac{N_{e}}{K}\right)^{2} \\
T_{t} & =T_{p} \cdot T R
\end{aligned}
$$

where $T_{p}$ is the pump torque, $K$ is the capacity factor, $T_{t}$ is the turbine torque, and $T R$ is the torque ratio. $K$ and $T R$ are functions of speed ratio, SR (see Fig. 3), which is defined as the ratio between the input speed and output speed of the torque converter, i.e.,

$$
\mathrm{SR}=\frac{N_{t}}{N_{e}}
$$

Since the engine speed is computed from the engine model and the turbine speed is calculated from the vehicle speed using the tire radius, the final drive ratio, and the gear ratios, the speed ratio is known. The capacity factor and the torque ratio can be calculated using the data table shown in Fig. 3. Equations (2) and (3) are then used to calculate the pump torque and the turbine torque.

\section{Transmission Gear Box}

Since the main purpose of this study is to obtain the optimal shift point with respect to throttle opening and vehicle speed, shift transient characteristics are not considered. Therefore, the detailed shift mechanisms such as the clutches, the gear sets, and the hydraulic systems and in-between shift phenomena are

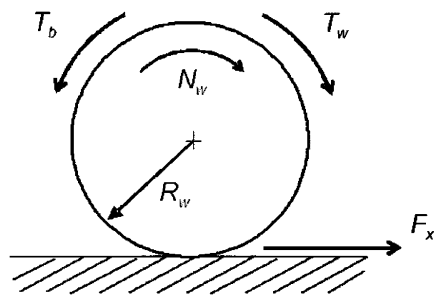

Fig. 4. Wheel rotation.

ignored. The transmission gear box is modeled as a simple algebraic I/O relation with the gear ratios $\left(\xi_{\mathrm{GR}}\right)$ only taking into account the efficiency of each gear $\left(\eta_{\mathrm{GR}}\right)$. The input/output relationships are governed by

$$
\begin{aligned}
T_{\text {output }} & =T_{t} \cdot \xi_{\mathrm{GR}} \cdot \eta_{\mathrm{GR}} \\
T_{w} & =T_{\text {output }} \cdot \xi_{\mathrm{FD}} \cdot \eta_{\mathrm{FD}} \\
N_{t} & =N_{\text {output }} \cdot \xi_{\mathrm{GR}} \\
N_{\text {output }} & =N_{w} \cdot \xi_{\mathrm{FD}} \cdot
\end{aligned}
$$

$T_{t}$ from the torque converter is used to calculate the output torque $T_{\text {output }}$ from the transmission gearbox, which is then multiplied by the final drive ratio $\xi_{\mathrm{FD}}$, and the final drive efficiency $\eta_{\mathrm{FD}}$, to obtain the driving torque $T_{w}$. $N_{\text {output }}$ is the rotational speed of the transmission gearbox output shaft and is calculated using $\xi_{\mathrm{FD}}$ and the wheel rotational speed $N_{w}$, obtained from (13). Then, $N_{\text {output }}$ is used to obtain the $N_{t}$. It is not possible to calculate the turbine rotational speed directly from the torque converter because the inertia of the turbine shaft is neglected. The turbine rotational speed is thus obtained in this reverse calculation manner.

\section{Tire/Vehicle Body Dynamics}

A point-mass model is used to represent the vehicle body, which is described by

$$
\dot{V}=F_{x}-\frac{\left(F_{\text {aero }}+F_{\text {roll }}+F_{\text {gradient }}\right)}{M_{v}}
$$

where

$$
\begin{aligned}
F_{\text {aero }} & =\frac{\rho}{2} \cdot C_{d} \cdot A \cdot V^{2} \\
F_{\text {roll }} & =K_{r r} \cdot M_{v} \cdot g \cdot \cos \theta \\
F_{\text {gradient }} & =M_{v} \cdot g \cdot \sin \theta
\end{aligned}
$$

and $V$ is the vehicle forward speed. The three resisting forces in (9) are the aerodynamic drag $F_{\text {aero }}$, rolling resistance $F_{\text {roll }}$, and road grade $F_{\text {gradient }}$. These forces are governed by the vehicle frontal area $A$, coefficient of aerodynamic resistance $C_{d}$, mass density of air $\rho$, rolling resistance coefficient $K_{r r}$, vehicle mass $M_{v}$, gravity constant $g$, and road grade $\theta$.

The wheel rotational speed, $N_{w}$ is calculated from

$$
\dot{N}_{w}=\frac{\left(\left(T_{w}-T_{b}\right)-F_{x} \cdot R_{w}\right)}{\left(I_{w}+I_{G}\right)}
$$

by using the driving torque $T_{w}$, brake torque $T_{b}$, wheel radius $R_{w}$, inertia of wheel and axle $I_{w}$, inertia of drive-train $I_{G}$, and 
TABLE II

WOT RESUlTS (VEHICLE TEST VERSUS SiMULATION)

\begin{tabular}{lcc}
\hline \multicolumn{1}{c}{ WOT Performance } & Test & Simulation \\
\hline Speed, @ 1/4 mile (mph) & 80.94 & 80.56 \\
Time, $0-1 / 4$ mile (sec) & 17.71 & 17.72 \\
Time, $0-60 \mathrm{mph}(\mathrm{sec})$ & 10.06 & 9.96 \\
\hline
\end{tabular}

TABLE III

EPA Fuel Economy Cycle Results (Vehicle Test Versus Simulation)

\begin{tabular}{ccc}
\hline EPA cycle & Test & Simulation \\
\hline City $(\%)$ & 100 & 106 \\
Highway $(\%)$ & 100 & 104 \\
\hline
\end{tabular}

traction force $F_{x}$ (see Fig. 4). The tire traction force is obtained from a lookup table with the tire slip ratio $S$ as input

$$
\begin{gathered}
\left.S_{x}=\frac{\left(N_{w} \cdot R_{w}-V\right)}{\left(N_{w} \cdot R_{w}\right)} \quad \text { (when slipping: } N_{w} \cdot R_{w} \geq V\right) \\
\left.S_{b}=\frac{\left(V-N_{w} \cdot R_{w}\right)}{V} \quad \text { (when skidding: } V>N_{w} \cdot R_{w}\right) .
\end{gathered}
$$

\section{E. Model Validation}

The model developed in Section I is validated by comparing the simulation results to the test results of the target vehicle in two scenarios: wide-open-throttle (WOT) launching and the EPA fuel economy test cycles. The WOT test provides widely used performance indicators, such as speed at quarter mile, time to quarter mile, and time from 0 to $60 \mathrm{~m} / \mathrm{h}$. The EPA cycle results are important because they are the standard yardstick for vehicle fuel economy results. In order to follow the EPA cycles, a driver model is constructed based on a proportional plus feedforward controller. The feedforward signal and the proportional gain are designed iteratively to ensure the speed error is within the EPA tracking accuracy requirement without excessive oscillatory control actions. The model validation results are shown in Tables II and III. The simulation results are all higher then the test data mainly because all of the losses that occur in the real vehicle are not accounted for in the model. However, the simulation results are all within $6 \%$ of the test data. From these results, we conclude that the simulation model is accurate enough for the integrated powertrain control design and evaluations.

\section{Optimal Throttle/Gear Control StRategy GENERATION WITH ETC SYSTEM}

The format of the gear-shift schedule currently used in the industry is a 2-D map with throttle opening and vehicle velocity as independent variables. The gear-shift map of this form covers the throttle opening from $0 \%$ to $100 \%$ and the vehicle speed from $0 \mathrm{~m} / \mathrm{h}$ to the maximum velocity the vehicle can reach at WOT. Because the method of assessing a gear-shift schedule for fuel efficiency is to evaluate the fuel economy over a specified drive cycle, it would be ideal to optimize the gear-shift schedule along this drive cycle. However, in many cases, vehicles need only up to about $40 \%$ throttle to follow the drive cycle.
Also, the maximum velocity of the test cycle used in the U.S. is $60 \mathrm{~m} / \mathrm{h}(96.6 \mathrm{k} / \mathrm{h})$, meaning that if the gear-shift schedule is optimized along the drive cycle, data obtained will only cover less than half of a gear-shift map. Moreover, since the fuel economy test drive cycles do not include any specifications for performance, a gear-shift schedule based on the drive cycle may not be drivable in real life driving situations. In order to overcome the shortcomings of optimizing the gear-shift schedule over a drive cycle, "constant pedal (power) launching" maneuvers are used for optimization in this paper. These "launching" maneuvers are important because they exert a significant influence on vehicle fuel economy. In addition, we assume that providing constant power in these launching maneuvers will provide acceptable (or improved) perceived drivability. DP technique is used to optimize the gear-shift schedule for constant power demands of $10 \%, 20 \%, \ldots, 100 \%$. The results for each power level are then combined to form a throttle/gear map.

DP [8]-[12] is a multistage decision-making process for dynamic systems, which guarantees global optimal solution up to the grid accuracy. Furthermore, it is flexible in accommodating equality and inequality constraints. Due to these advantages many studies in the field of powertrain control have used the DP technique [13]-[15]. However, the use of dynamic programming has several limitations. The one with the most impact is the extremely high computational load, which is well known as the "curse of dimensionality." As the number of state and control variables increase, the computational problems regarding the storage of the data and the time it requires to perform the computation increase exponentially. Thus, dynamic programming is feasible only for systems with a low number of states and a small number of grid points. Another of its limitations is that only quantifiable and accumulative goals can be used.

In this paper, the discrete deterministic version of dynamic programming is applied. It is deterministic, as opposed to stochastic, because it is assumed that the outcome of a control decision is uniquely determined by the decision. It is discrete because it is generally easier to solve a multistage decision making problem numerically. In addition, it is no easy task to obtain an analytical solution when the dynamic system is highly nonlinear and lookup tables are used in the system modeling, as is the case in this study.

\section{A. DP Vehicle Model}

To minimize the computational load involved in DP optimization process, it is important to capture only the essential states for the intended optimization process. Since launching maneuvers are selected for the optimization, possibilities of further simplification of the vehicle simulation model without sacrificing the accuracy of launching maneuvers were explored. Fig. 5 shows the WOT simulation results using the vehicle simulation model with and without tire-slip model. It shows that the launching behavior of the simplified model (without tire slip) is very similar to the original model (with tire slip). This simplified model reduces the number of state variables by one, from four to three, which results in lowered computation load in DP. Therefore, it is used as the DP vehicle model. 

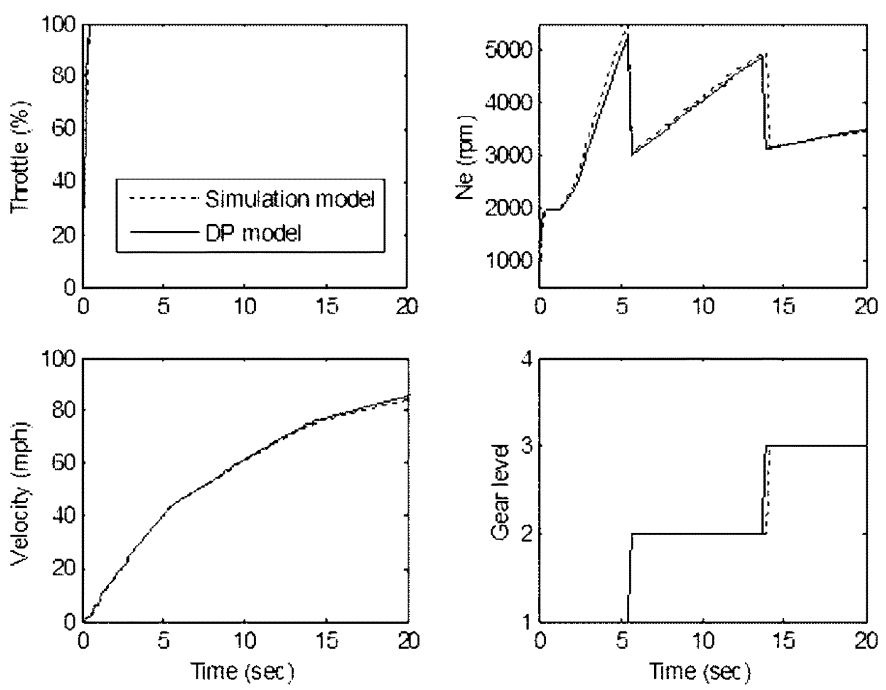

Fig. 5. WOT simulation results (vehicle simulation model versus DP vehicle model).

Based on this model, state variables and control signals are all discretized for DP implementation. The grid sizes of these elements are important because they are directly related to the simulation accuracy and computation time. Small grid sizes lead to longer computation time but more accurate optimization results. It is also important that the sampling time step size is large enough so that the state variables could evolve to adjacent grid points. The selected grid points are as follows.

Driver Demand:

Power [\%] [10:10:100].

Control Inputs:

Gear Shift $\quad G_{s}:-1,0,1$;

Throttle [\%] Th: [0:2:100].

States:

$$
\begin{array}{ll}
\text { Engine speed }[\mathrm{r} / \mathrm{min}] & N_{e}:[600: 50: 6000] \\
\text { Gear position } & G_{p}:[1,2,3,4] \\
\text { Vehicle speed }[\mathrm{m} / \mathrm{h}] & V:[0: 1: 120] .
\end{array}
$$

\section{B. Cost Function and Constraints}

The goal of the DP problem in this study is to find the optimal gear control and throttle angle for the target vehicle maximizing the fuel economy while satisfying the driver's power demand. Since the cost function of DP needs to be expressed in an accumulative fashion we cannot directly express fuel economy, which is distance traveled over fuel consumed, in the cost function. Therefore, the stage parameter for DP is chosen to be a fixed distance and the cost function is set to minimize the fuel consumed. The problem setup is as follows.

Choose $u(k)(k=0,1, \ldots, N-1)$ to minimize the cost function

$$
J=G_{N}(x(N))+\sum_{k=0}^{N-1} L_{k}(x(k), u(k))
$$
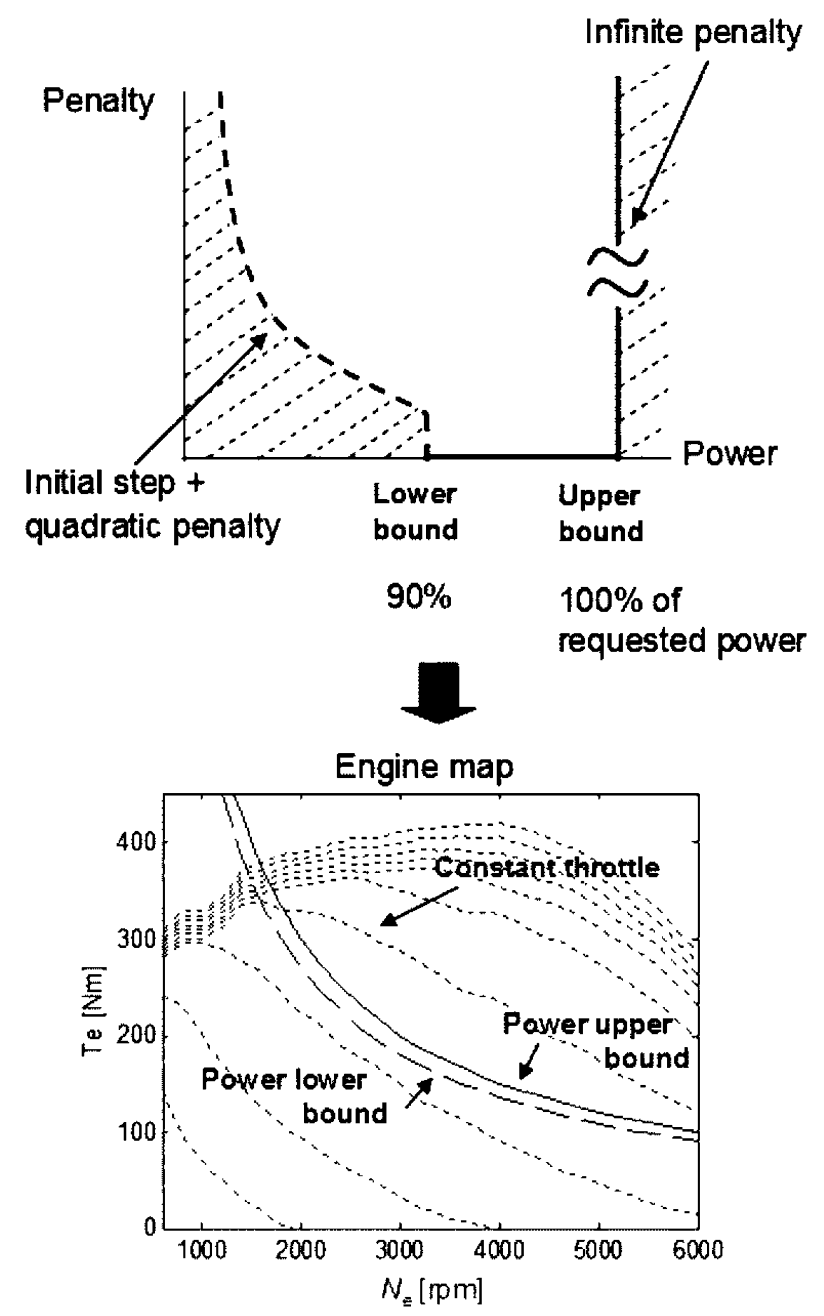

Fig. 6. Power band penalty.

where

$$
x(k+1)=f(x(k), u(k)), \quad k=0,1, \ldots, N-1 .
$$

Here, $x(k)$ is the state vector of $\left[N_{e}, G_{p}, V\right]$ at stage $k, u(k)$ is the control vector of $\left[G_{s}, T h\right], f$ is the transition function that represents the system model (DP vehicle model), $L$ is the instantaneous transition cost (fuel consumption) at stage $k$, and $G_{N}$ is the cost (fuel consumption) at the final stage $N$.

The mapping between pedal position ( $0 \%$ to $100 \%)$ and desired engine power $(0 \%$ to $100 \%)$ can be designed to achieve different perceived driving quality. However, in this study, we simply assume that a certain power demand is given (without specifying what the corresponding pedal position is). The optimization problem is then solved to achieve the specified power level in an optimal fashion. Another factor to be considered is the fact that since all the control variables are discretized in the DP optimization process, it will not be possible to find an optimal solution that provides a perfectly constant power. Therefore, the driver power demand is converted into an acceptable power band and implemented in the DP optimization process as inequality constraints. The corresponding penalty functions for the constraints are shown in Fig. 6. 


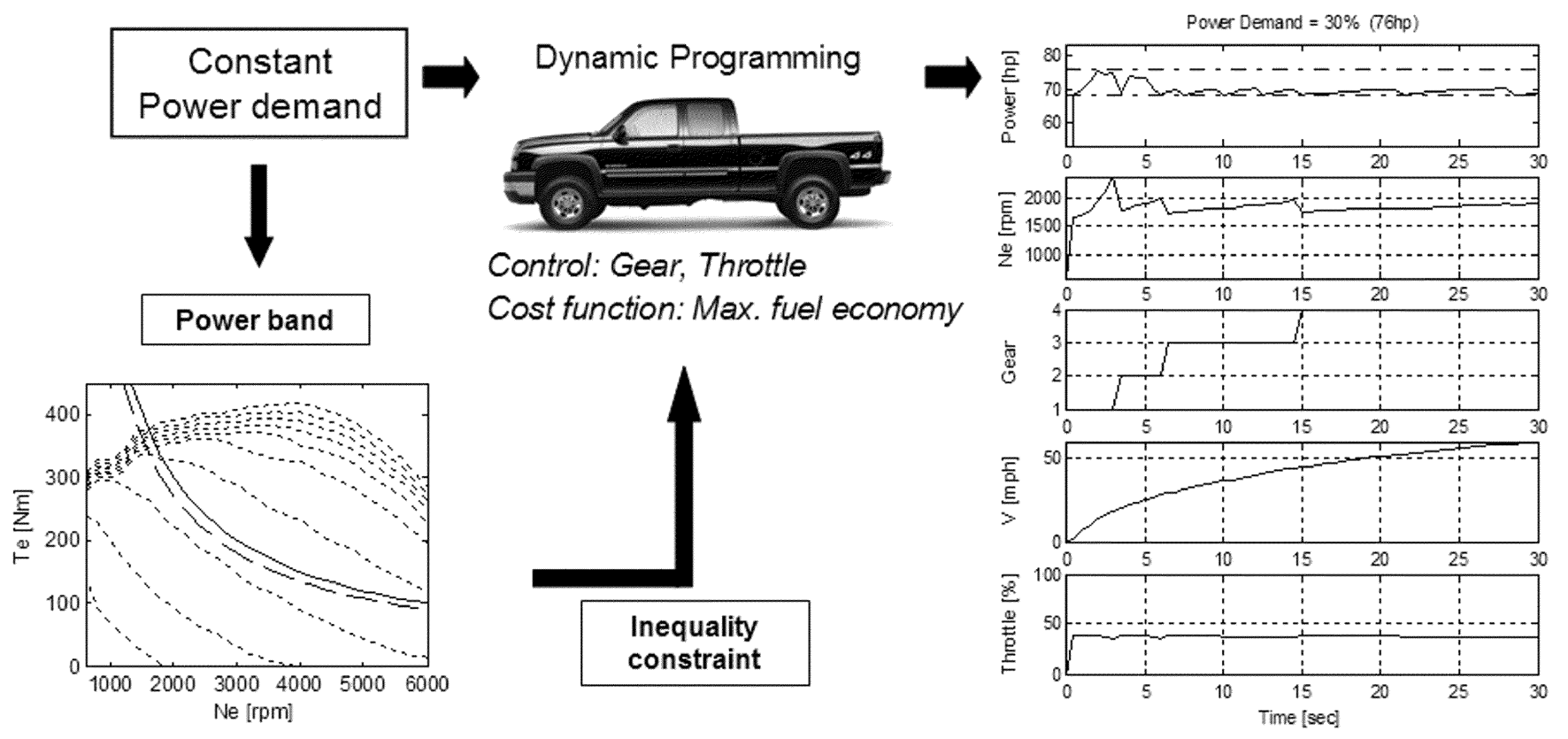

Fig. 7. Procedure to obtain integrated throttle/gear shift control.
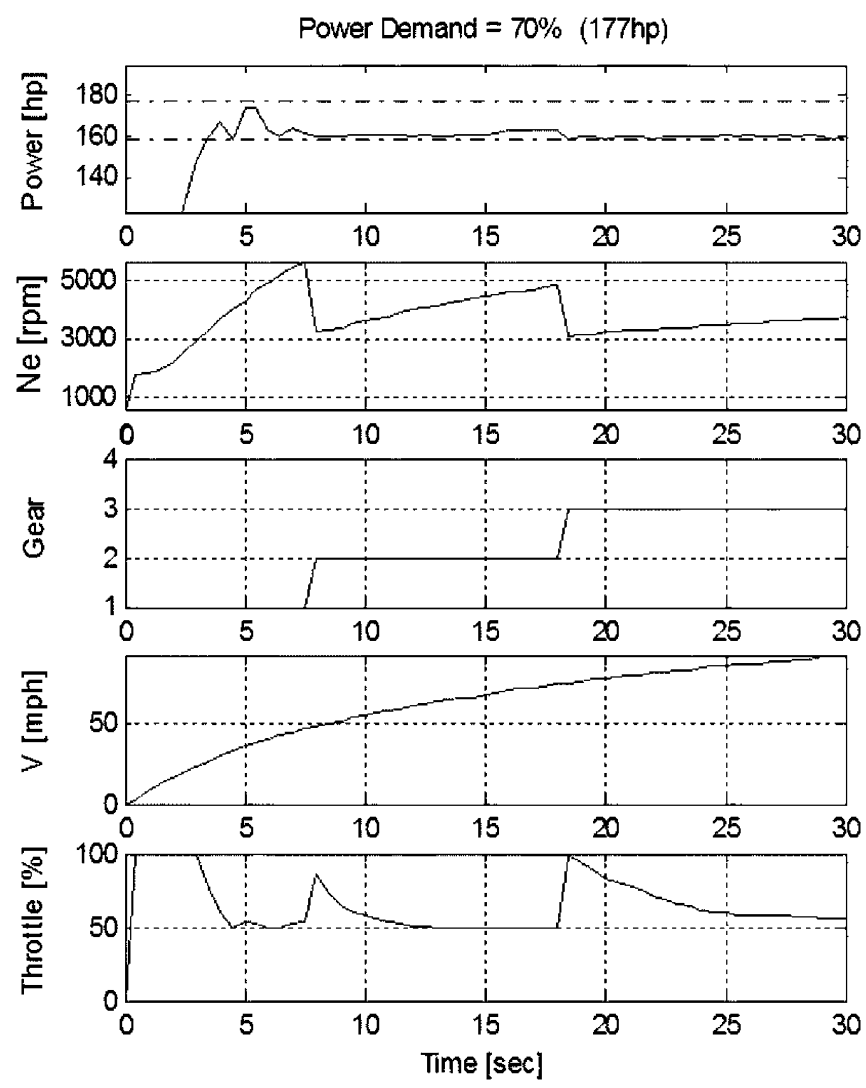

Fig. 8. DP optimization results for $70 \%$ power demand.

The requested power is used as the upper bound (shown as a solid line in Fig. 6) of the power band and the power values above this bound will be given infinite penalty since it is not acceptable to provide more power than demanded. The lower bound (shown as a dashed line in Fig. 6) will be $90 \%$ of the demanded power. In other words, as long as the generated power is in between $90 \%$ and $100 \%$ of the requested power, no penalty will be assigned. A finite penalty will be given at
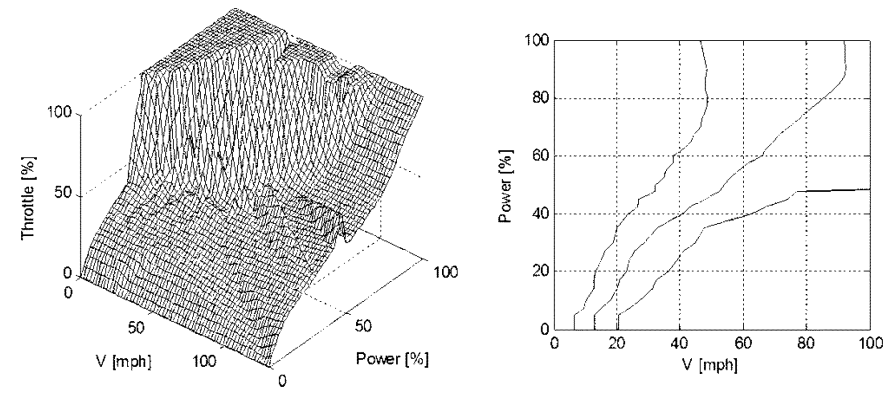

Fig. 9. (left) Throttle map. (right) Gear map.

the lower bound of the band and the penalty weight increases in a quadratic manner. The lower bound of the power band is defined in this way to give a leeway to the DP process for cases where the optimal solution cannot be found within $90 \%$ and $100 \%$ of the demanded power.

\section{Control Strategy Generation}

For a given power demand, the power demand is converted into a power band constraint. Then, the DP problem is solved to obtain the optimal control strategy of the gear shift and the throttle opening that maximizes the fuel economy while satisfying the power band constraint. The procedure is depicted in Fig. 7. Optimization results at $30 \%$ and $70 \%$ power demands can be seen in Figs. 7 and 8, respectively. In the first plots of the figures, the solid lines show the actual power produced by the engine and the dash-dot lines represent the power band. A very noticeable feature is that the throttle opening was manipulated so that the generated engine power stays within the specified power band when the gear shifts were made. This constant power demand optimization procedure is repeated for power demands of $10 \%, 20 \%, \ldots, 100 \%$ of the full power. Then, the gear map is constructed by combining all the velocity points where the gear shifts are made for all power levels and the throttle map is constructed in the same manner as the gear map where the 


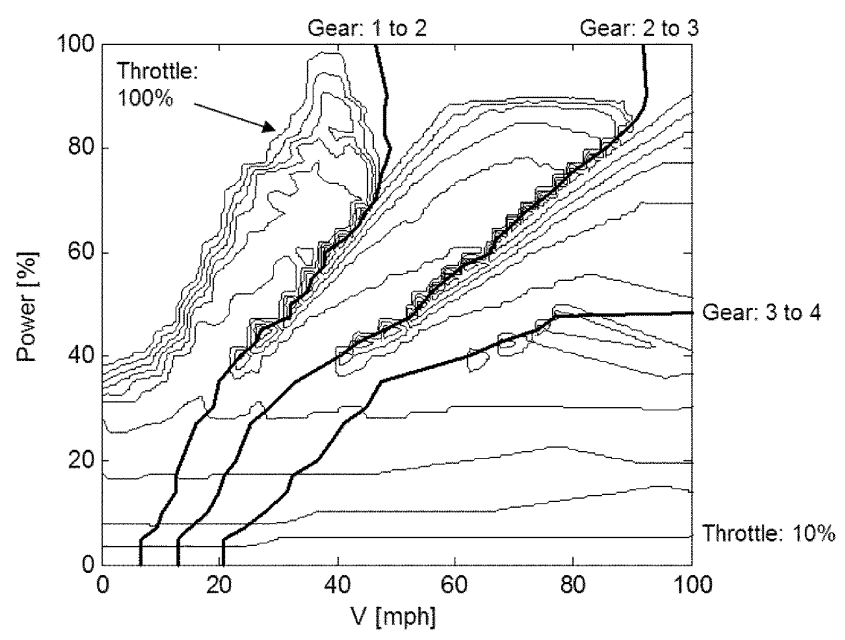

Fig. 10. ETC throttle/gear map.

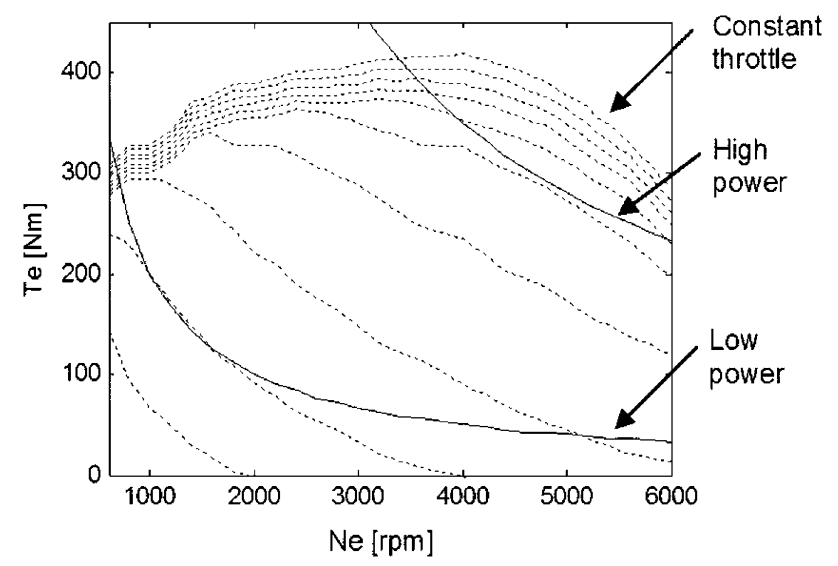

Fig. 11. Constant power lines on engine torque map.

TABLE IV

EPA Fuel ECONOMy CyCle Simulation Results

\begin{tabular}{ccc}
\hline EPA cycle & $\begin{array}{c}\text { Production strategy } \\
\text { (non-ETC) }\end{array}$ & DP strategy (ETC) \\
\hline City (\%) & 100 & 104 \\
Highway (\%) & 100 & 100 \\
\hline
\end{tabular}

resulting throttle profiles are represented with respect to the velocity profiles. The resulting throttle map and the gear map are shown in Fig. 9. These two maps can be overlapped for better visualization, as shown in Fig. 10. At low power demand level (up to $20 \%$ ), there is no significant difference from ETC and conventional mechanical throttle control system. In other words, the throttle is almost constant and does not fluctuate when a gear shift is made. This is due to the fact at low throttle level, constant throttle line correspond to constant power line closely as shown in Fig. 11. At mid to high power levels, peculiar throttle behavior is observed. First, at low vehicle speed, the throttle is almost at WOT position to reach the power level demanded by the driver as quickly as possible. Second, the throttle shows a sudden surge at gear shifting points and slowly decays to a steady-state level. Had the throttle opening been held constant after a gear shift, the engine speed would decrease and the engine torque would increase. However, the amount of increase of the engine torque
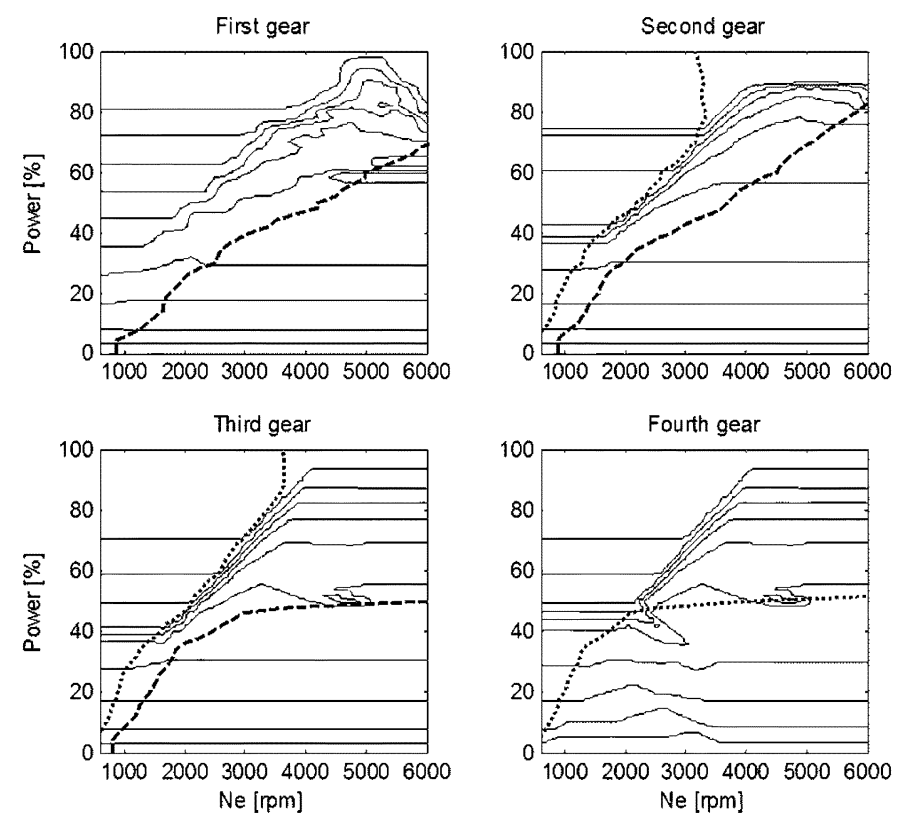

Fig. 12. Modified throttle map.

would not be enough to maintain the engine power. Therefore, the surge of the throttle is needed to increase the engine torque to compensate for the power loss during the shift. The throttle then decays as the engine speed increases.

\section{Evaluation of the New Control Strategy}

The obtained throttle and gear shift maps are implemented in the vehicle simulation model presented in Section II to evaluate the performance of the vehicle.

Table IV shows that by controlling the throttle/gear map together, the ETC system achieves higher fuel efficiency than the current production map by about $4 \%$ for the city cycle. Even though this comparison is not fair (the ETC achieves almost constant power while the non-ETC achieves fluctuating power), the improved fuel economy indicates that imposing constant power requirement does not result in fuel economy penalty. The ETC maps were also implemented in the test vehicle for actual drive feel evaluations. After preliminary test drives, two issues were identified. First, the high throttle surges at mid power levels at low speeds were found to be disturbing although it helps to reach the demanded power more quickly. This problem was resolved by modifying how the driver demand for DP optimization is set. Instead of setting the driver demand as a step function, a rate limiter is used. The second issue was the independent operation of the shift map and the throttle map. When there is no gear shift delays the throttle surging behavior at high power demand regions will match the point of gear shift since they are commanded simultaneously. However, on the test vehicle, the throttle rises before the shifts were made due to the gear shift delays. Therefore, additional coordination between the two control actions is needed. The coordination is achieved by splitting the throttle map into four maps, one for each gear, and the independent variables of the maps are power demand and engine speed (rather than power demand and vehicle speed). The modified throttle map is shown in Fig. 12. The solid lines are contour 


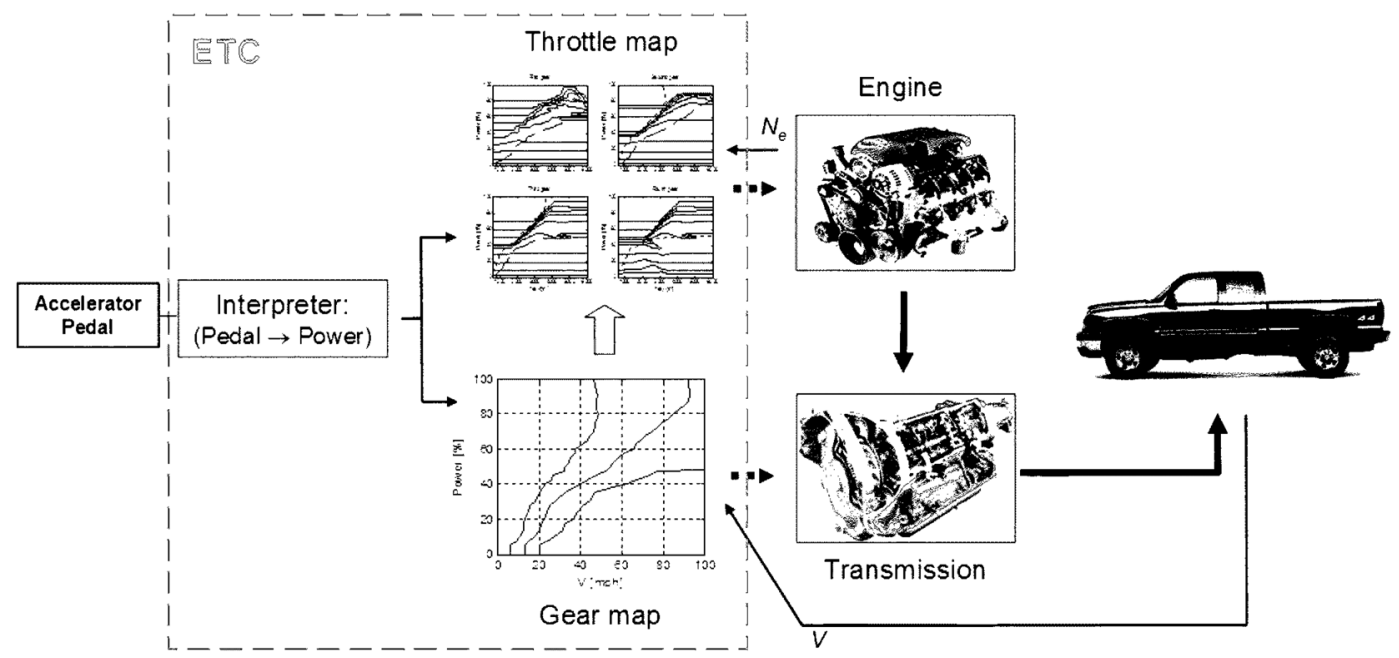

Fig. 13. Throttle/gear map implementation for the integrated powertrain control scheme.
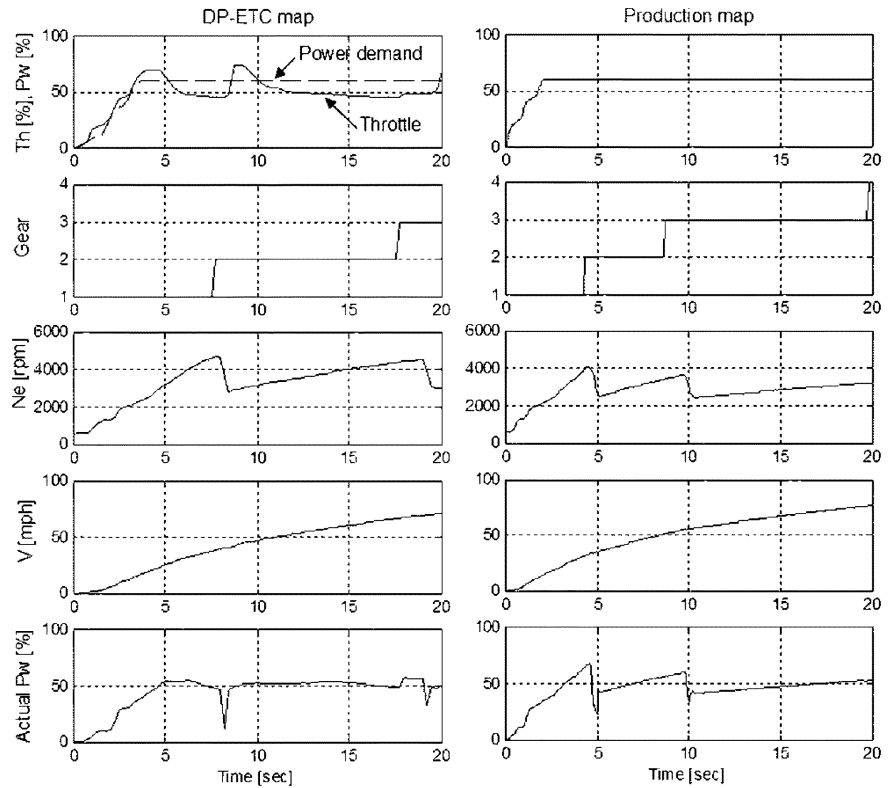

Fig. 14. Modified throttle map.

lines representing the throttle levels of $10 \%, 20 \%, \ldots, 100 \%$. The dotted lines show where the up-shifts and the downshifts are made. In this format, the drop of the engine speed after the gear up-shift will trigger the throttle command to surge. Fig. 13 shows the overall configuration which achieves throttles and gear control as an integrated unit.

In-vehicle testing showed that the ETC throttle/gear map does provide almost constant power as intended (see Fig. 14). For comparison, a test result from a non-ETC vehicle with constant throttle level is also shown. The bottom two plots show the actual power produced by the engine calculated from engine speed and engine torque. The power produced using the ETC throttle/gear map (left) is almost flat except during shifts. This enhanced the overall shift feel since there is no power loss after the shift as was the case for non-ETC vehicles.

Chassis dynamometer tests were also conducted to evaluate the fuel efficiency of the ETC throttle/gear map. Both the ETC throttle/gear map and the production (non-ETC) map were used in the target vehicle to follow the EPA city and the highway
TABLE V

EPA FuEl ECONOMY CyCle DyNAMOMETER TEST RESUltS

\begin{tabular}{ccc}
\hline EPA cycle & $\begin{array}{c}\text { Production strategy } \\
\text { (non-ETC) }\end{array}$ & DP strategy (ETC) \\
\hline City $(\%)$ & 100,100 & 102,101 \\
Highway $(\%)$ & 100,100 & 101,101 \\
\hline
\end{tabular}

cycle on the dynamometer. Table $\mathrm{V}$ shows that for both the city cycle and the highway cycle ETC throttle/gear map achieves slightly better fuel economy.

Although the improvements in the EPA cycle results might not seem significant, two facts have to be taken into consideration. One is that it only takes a couple of days to construct a gear/throttle map using the proposed design procedure whereas the current practice of constructing a gear map takes several months. The other is that the current production gear map has been refined by highly experienced calibration engineers for many years.

\section{E. Flexible Control Architecture}

The accelerator pedal position was interpreted as a power demand in this paper. The pedal angle progression could be tuned to provide desired perceived performance which is beyond the scope of this paper. We believe the throttle progression mapping needs to be obtained through extensive human subjective evaluation and is more art than science. In addition, the pedal position progression mapping is highly dependent on the preference of the costumer group the vehicle is targeting. Therefore, program chief engineers could adjust the "interpreter" block shown in Fig. 15 to suit the target audience. On the other hand, once this mapping is determined, how the demanded power can be generated optimally by the powertrain is pure science, and thus the throttle/gear maps are reusable across vehicle platforms. This reusable control architecture is depicted in Fig. 15.

\section{CONCLUSION}

An optimal control strategy for integrated transmission and ETC system is developed using the DP approach. In the proposed design procedure, the driver pedal motion is interpreted 


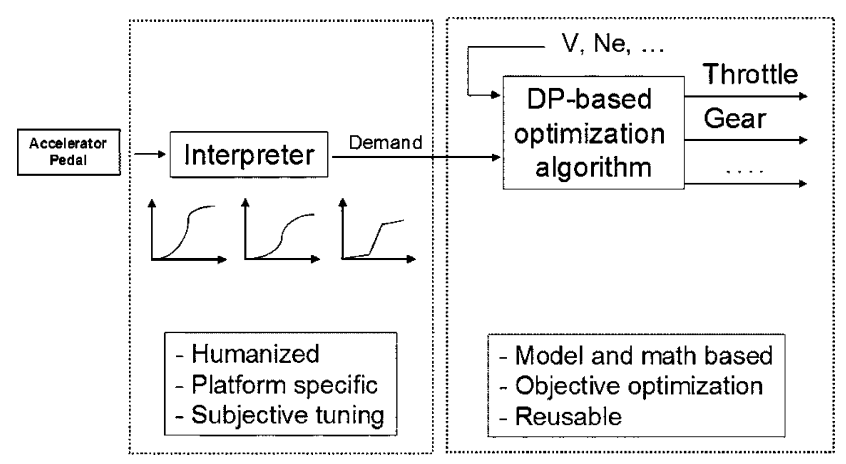

Fig. 15. Flexible pedal position progression mapping.

as a power demand. The integrated transmission/ETC control algorithm then is obtained through DP to achieve the requested power level in the most fuel efficient way.

In-vehicle testing shows that the obtained transmission shift map and the throttle map generate surprisingly drivable vehicle performance. Moreover, EPA city and highway cycle tests conducted on a dynamometer show fuel economy improvement compared to current (non-ETC) production map. One attractive feature of the proposed control algorithm is the fact very consistent power is generated through the coordination of engine and transmission operations. In addition, this control architecture clearly separates the subjective part (interpretation of driver demand to power) and objective part (integrated control of transmission/ETC to meet the demanded power) of the overall design, which improves the reusability of the overall control system.

\section{REFERENCES}

[1] M. Costin, R. Schaller, M. Maiorana, J. Purcell, R. Simon, P. Bauerle, and J. Stockbridge, "An architecture for electronic throttle control systems," SAE Int., Warrendale, PA, 2003-01-0098, 2003.

[2] H. Steib and G. Bischof, "Electronic throttle control (ETC): A cost effective system for improved emissions, fuel economy, and driveability," SAE Int., Warrendale, PA, 960338, 1996.

[3] A. Ge, G. Qin, S. Ge, and H. Li, "Drive-by-wire (DBW) control of power train system during the automatic shifting," SAE Int., Warrendale, PA, 9530841, 1995.

[4] T. Minowa, H. Kimura, N. Ozaki, and M. Ibamoto, "Improvement of fuel consumption for a vehicle with an automatic transmission using driven power control with a powertrain model," JSAE Rev., vol. 17, pp. 375-380, 1996

[5] M. Yasuoka, M. Uchida, S. Katakura, and T. Yoshino, "An integrated control algorithm for an SI engine and a CVT," SAE Int., Warrendale, PA, 1999-01-0752, 1999.

[6] S. Sakaguchi, E. Kimura, and K. Yamamoto, "Development of an engine-CVT integrated control system," SAE Int., Warrendale, PA, 1999-01-0754, 1999.

[7] H. Vahabzadeh and S. M. Linzell, "Modeling, simulation, and control implementation for a split torque, geared neutral, infinitely variable transmission," SAE Int., Warrendale, PA, 910409, 1991.

[8] R. E. Bellman, Dynamic Programming. Princeton, NJ: Princeton Univ. Press, 1957.

[9] D. E. Kirk, Optimal Control Theory: An Introduction. Englewood Cliffs, NJ: Prentice-Hall, 1970.

[10] I. McCausland, Introduction to Optimal Control. New York: Wiley, 1969.

[11] B. Gluss, An Elementary Introduction to Dynamic Programming: A State Equation Approach. Boston, MA: Allyn \& Bacon, 1972.
[12] L. Cooper and M. W. Cooper, Introduction to Dynamic Programming. New York: Pergamon, 1981.

[13] J. Kang, I. Kolmanovsky, and J. Grizzle, "Dynamic optimization of lean burn engine aftertreatment," J. Dyn. Syst., Meas. Contol, vol. 123, pp. 153-160, Jun. 2001.

[14] C. C. Lin, J. Kang, J. Grizzle, and H. Peng, "Energy management strategy for a parallel hybrid electric truck," in Proc. Amer. Control Conf., 2001, pp. 2878-2883.

[15] I. Kolmanovsky, O. Siverguina, and B. Lygoe, "Optimization of powertrain operating policy for feasibility assessment and calibration: Stochastic dynamic programming approach," in Proc. Amer. Control Conf., 2002, pp. 1425-1430.

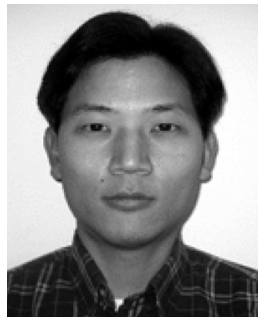

Daekyun Kim received the B.S. and M.S. degrees in mechanical production and design engineering from Seoul National University, Seoul, Korea, in 2000 and 2002, respectively, and the Ph.D. degree in mechanical engineering from the University of Michigan, Ann Arbor, in 2006.

$\mathrm{He}$ is currently a Researcher at General Motors Research and Development and Strategic Planning, Warren, MI. His research interests include vehicle dynamics and control and optimization of automotive transmission systems.

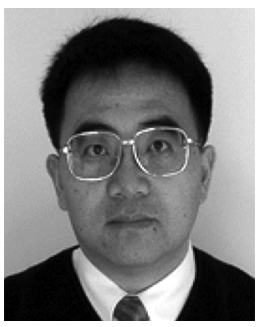

Huei Peng received the Ph.D. degree in mechanical engineering from the University of California, Berkeley, in 1992.

He is currently a Professor in the Department of Mechanical Engineering, University of Michigan, Ann Arbor. He is also the Director of Automotive Engineering Program of the University of Michigan. His research interests include adaptive control and optimal control, with emphasis on their applications to vehicular and transportation systems.

Dr. Peng has been an active Member of the Society of Automotive Engineers (SAE) and the Dynamic System and Control Division, American Society of Mechanical Engineers (ASME), New York. He was a recipient of the National Science Foundation (NSF) Career Award in 1998. He has served as the chair of the ASME DSCD Transportation Panel from 1995 to 1997. He is currently an Associate Editor for the IEEE/ASME TRANSACTIONS ON MECHATRONICS.

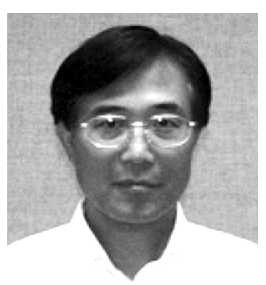

Shushan Bai received the B.S. degree in mechanical engineering from the Hauzhong Institute of Technology, Hauzhong, China, in 1976, and the M.S. and Ph.D. degrees in electrical engineering from Hokkaido University, Hokkaido, Japan, in 1983 and 1986, respectively.

He is currently a Senior Staff Project Engineer at General Motors Powertrain, Ypsilanti, MI. He is also an Adjunctive Faculty at the Department of Mechanical Engineering, University of Michigan, Ann Arbor. His research interests include vehicle dynamic analysis and control automatic transmissions and optimal control powertrain systems.

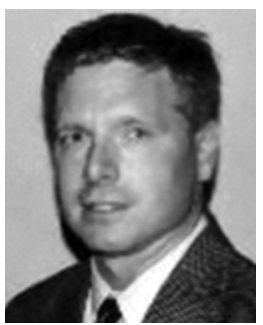

Joel M. Maguire received the B.S. degree in mechanical engineering from Michigan Technology University, Houghton, in 1985, with an emphasis on design, and the M.S. degree in mechanical engineering from Rennsselaer Polytechnic Institute, Troy, NY, in 1992.

$\mathrm{He}$ is currently an Engineering Group Manager of Advanced Hybrids Group in General Motors Powertrain, Pontiac, MI. His research interests include vehicle driveline, transmissions, hybrids, and the integration of these technologies. 